\title{
THE SIGNIFICANCE OF TRANSPULMONARY PRESSURE CHANGES IN CHILDREN ANAESTHETIZED FOR CARDIAC SURGERY - ANALYIS OF RESPIRATORY MECHANICS*
}

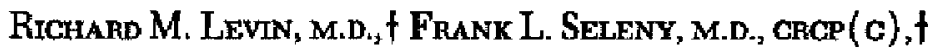 \\ C.W. JOSH, M.D., † AND MichaEL V. STRECZYN $\nmid$
}

THE PURPOSE OF THIS STUDY was to find a simple objective measurement of respiratory function which would serve as an indicator of impending respiratory failure in paediatric patients after cardiac surgery.

It is difficult to predict, preoperatively, which patients will need respiratory assistance postoperatively, especially after cardiopulmonary procedures. Failure, to ventilate, when such assistance is later required, exposes the patient to a potentially dangerous period of hypercarbia and hypoxia. Artificial ventilation of all postoperative cardiac cases on the other hand can create additional respiratory problems in a delicate phase of the recovery room care. ${ }^{1}$ To be more selective, many physicians assess the subjective clinical signs of ventilation, combined with blood gas determinations. ${ }^{2}$ These signs usually taken near the end of surgery are difficult to evaluate in the presence of residual anaesthesia, muscle relaxation and artificial ventilation with elevated inspired oxygen concentrations. It would be extremely useful to have a practical, objective parameter in the presence of these factors to indicate the need for ventilatory assistance. Our hypothesis was as follows:

(1) The inability of children to have adequate spontaneous respiration after cardiac surgery is caused primarily by pathologic changes present in the lungs. Cardiac and neurological considerations are most often secondary.

(2) Pathological changes within the lungs will increase the pressure needed to overcome resistive forces opposing pulmonary expansion. The presence of such elevated opposing forces has already been established in patients with increased pulmonary blood flow in pulmonary arterial hypertension ${ }^{a}$ as well as in other paediatric patients requiring ventilatory assistance."

(3) Consequently, inspiratory transpulmonary pressure, which measures the pressure required for lung inflation, may be a sensitive indicator as to the degree of underlying pulmonary pathology present. Since inspiratory transpulmonary pressure appears to be an objective parameter which could be readily measured during cardiac surgery (patients undergoing artificial ventilation) and might signal the need for postoperative ventilatory assistance, it was chosen to be examined for possible predictive value.

"Supported by Ortho S.A. Sprague Memorial Fund and NIH Grant FR 05475. Presented in part at the International Congress of Puediatrics, Vienna, Austria, September, 1971, and at the American Academy of Paediatrics, Anaesthesia Section, Chicago, Illinois, October, 1971.

fFrom the Department of Anesthesia, Northwestern University Medical School and Children's Memorial Hospital, Chicago, Illinois 60614. 
We therefore studied the characteristics of respiratory mechanics in anaesthetized infants and children while they were being ventilated by a volumecontrolled respirator. Measurements were made of airway pressure, transpulmonary pressure, pulmonary compliance and resistance.

\section{Materulas and Methods}

Prior to the beginning of this study four groups were set up according to the following criteria:

Group I Normal cardiopulmonary status (control group)

Group II Congenital heart disease, no pulmonary hypertension

Group III Congenital heart disease with pulmonary hypertension but no artificial ventilation required postoperatively

Group IV Congenital heart disease with pulmonary hypertension and need of artificial ventilation postoperatively

Patients selected for this study were then classified into these four groups after surgery was done. The decision to ventilate postoperatively was made by accepted conventional methods. ${ }^{\text {? }}$

One hundred and twenty-one patients ranging from 1 week to 15 years of age were investigated (Table I). Following routine premedication which consisted of pentazocine and atropine, the patients were anaesthetized with nitrous oxide, oxygen and halothane. A snug-fitting endotracheal tube was inserted after muscle relaxation produced by intravenous succinylcholine. When the anaesthetic level was stabilized, artificial ventilation was started by a volume-controlled respirator (Engstrom model \#200), with the airway pressure adjusted by varying the volume of ventilation to provide clinically adequate chest expansion. The respiratory rate was set according to a scale taken from the Engstrom nomogram:

$\begin{array}{cc}\text { Age (years) } & \text { Respirations per minute } \\ 0-2 & 26 \\ 2-4 & 24 \\ 4-8 & 22 \\ >8 & 20\end{array}$

Repeated samples of arterial blood were then taken for gas analysis as the volume of ventilation delivered by the respirator was adjusted until the arterial carbon dioxide tension remained between 30 and 35 torr for 15 minutes, or until a maximum airway pressure of 35 centimeters of water was reached.

All studies were performed on the patient in the supine position while anaesthesia was maintained with 50:50 nitrous oxide, oxygen, 1.5 per cent halothane, and preliminary procedures, such as peripheral and central intravenous catheter placement, were being done. An oesophageal balloon was passed to the level of the mid-oesophagus, using a technique similar to the one described by 


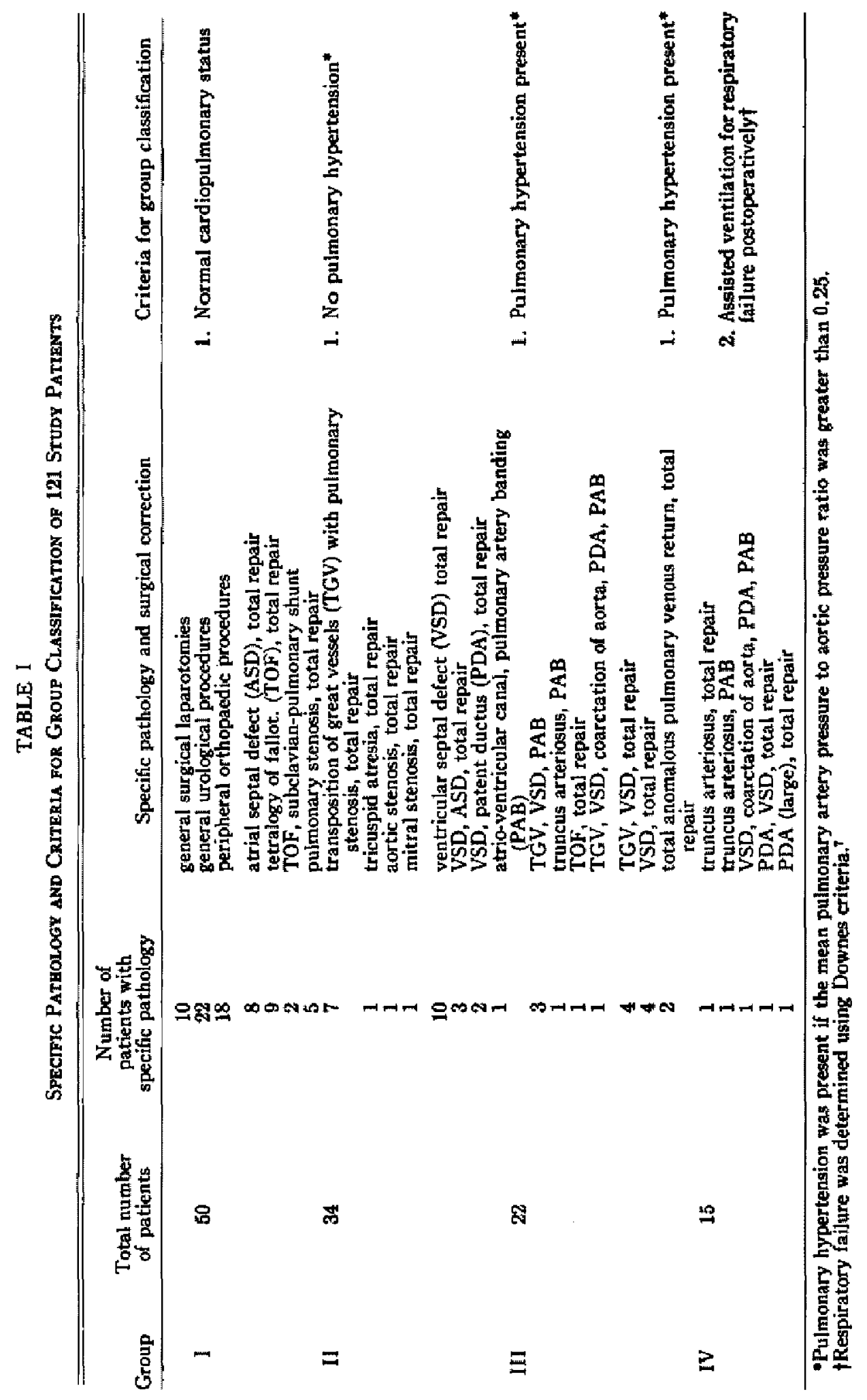




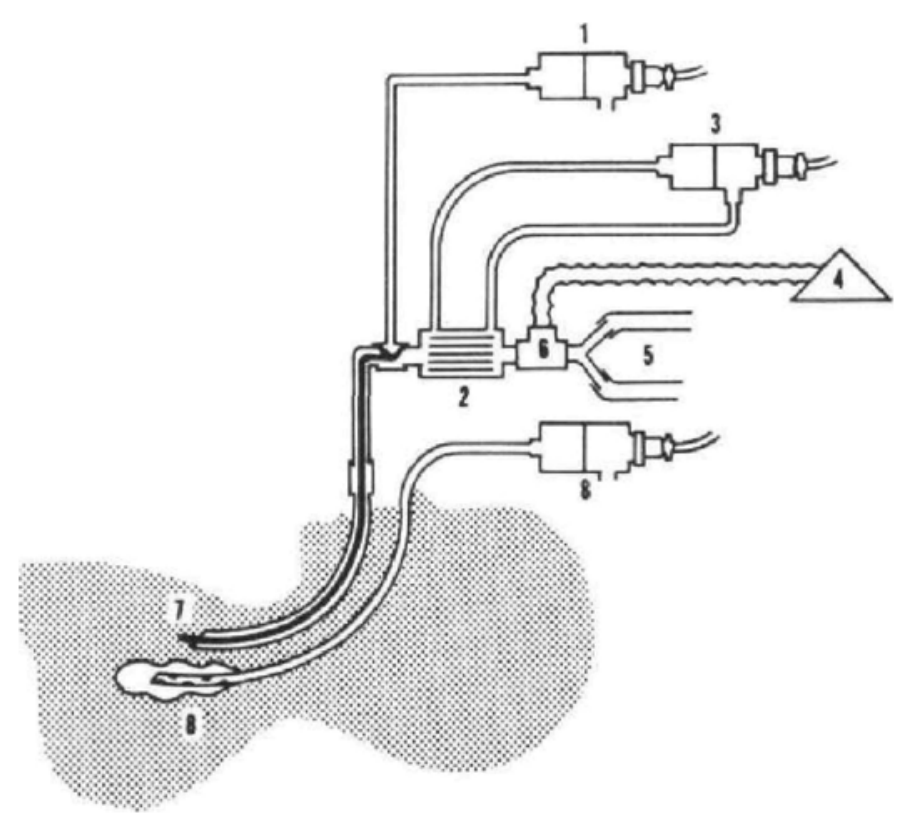

Figure 1. Schematic of experimental apparatus. 1, Pressure transducer (tracheal pressure). 2, Pneumotachograph (gas flow). 3, Gas pressure transducer. 4, Wedge spirometer (volume ventilation). 5, Engstrom circle tubing. 6, Sierra non-rebreathing valve. 7 , Endotracheal tube with No. 18 Fr. IV catheter inside (tracheal pressure). 8, Oesophageal balloon and pressure transducer (oesophageal pressure).

Krieger. ${ }^{4}$ The apparatus diagrammed in Figure 1 was inserted between the respirator " $Y$ " piece and the endotracheal tube. Respiratory flow measurements were obtained by means of a heated Fleisch pneumotachograph (No. 1, Instrumentation Associates) in conjunction with a Sanborn gas pressure transducer (Model \#270) and a Sanborn two-channel amplifier-recording system (350-1100C). The pneumotachograph (PTG) was calibrated with a 50 per cent nitrous oxide, oxygen gas mixture, and was linear to 50 liters per minute.

The exhalation port of a Sierra nonrebreathing valve, located between the PTG and the respirator " $\mathrm{Y}$ " piece, was connected with wide bore tubing and a large 2-way stopcock to a Wedge Spirometer (Model $* 370$ - Medical Science Electronics, Inc.). Thus in inspiration, the volume of ventilation passed through the PTG to the patient. In expiration, the patient's ventilation was directed back through the PTG and out the cxhalation port of the nonrebreathing valve to the spirometer. The compression volume of the respirator was thereby excluded from the spirometric collections. Accuracy of the Wedge Spirometer was checked with a calibrated giant syringe. The exhaled volume was collected for a minimum of 3 minutes, and the tidal volume was taken as the minute ventilation divided by the respiratory rate. 
The oesophageal balloon which measured intrathoracic pressure change ${ }^{3}\left(\Delta \mathrm{P}_{\mathrm{E}}\right)$ consisted of a latex fingercot securely attached to the perforated end of a \#12 Fr. teflon catheter. The long balloon $5.5 \mathrm{~cm}$ in length, was inserted into the oesophagus to the point where a maximum pressure change was obtained. After connecting the oesophageal balloon to a Sanborn pressure transducer-amplifier system (268B$1100 \mathrm{C}$ ), the balloon was filled with $0.2 \mathrm{ml}$ of air. The system was calibrated with a water manometer and was linear to $50 \mathrm{~cm}$ of water. Tracheal airway pressure change $\left(\Delta \mathrm{P}_{\mathrm{T}}\right)$ was measured with a \#18 gauge polyethylene catheter whose tip was inserted just distal to the opening of the endotracheal tube. The catheter was also connected to a Sanborn pressure transducer-amplifier system (268B-1100C).

Measurements were made of tracheal and oesophageal pressure change, gas flow rate and minute ventilation. Transpulmonary pressure (Ptp), pulmonary compliance $\left(C_{L}\right)$, and inspiratory pulmonary resistance $\left(\mathbf{R}_{\mathbf{F}_{1}}\right)$ were then calculated from these measurements.

Transpulmonary pressure (Ptp) was calculated by subtracting the inspiratory oesophageal pressure change from the tracheal pressure change both taken at endinspiration. End-inspiratory pressure measurements were used instead of peak pressure changes since they were taken from the plateau portion of the Engstrom pressure curve and are therefore less effected by variation in inspiratory flow rate. This measurement then represents to a greater degree the elastic portion versus the nonelastic portion of the inspiratory resistive pressure. ${ }^{5}$

Pulmonary compliance $\left(\mathrm{C}_{\mathrm{L}}\right)$ was calculated as the tidal volume per unit transpulmonary pressure.

$$
\mathrm{C}_{\mathrm{L}}=\frac{\mathrm{V}_{\mathbf{T}}}{\mathrm{Ptp}}
$$

This is dynamic compliance, measured during continuous respirations, but since calculations were made using the Engstrom plateau pressure, this value should more closely represent static compliance.

Inspiratory pulmonary resistance $\left(R_{P_{1}}\right)$ was calculated as the peak inspiratory pressure change $\left(\Delta \mathrm{P}_{\mathrm{T}}\right)$ minus the corresponding oesophageal pressure change $\left(\Delta \mathrm{P}_{\mathrm{K}}\right)$ per unit gas flow $(\dot{V})$ during inspiration.

$$
\mathbf{R}_{\mathbf{P}_{\mathrm{I}}}=\frac{\Delta \mathrm{P}_{\mathbf{T}}-\Delta \mathrm{P}_{\mathbf{E}}}{\dot{V}}
$$

Since the total resistive pressure was used in the calculation, this measurement inchudes all the elastic and nonelastic resistance of the airway and lung tissue opposing inflation, ${ }^{5,6}$ or the total inspiratory pulmonary resistance.

Pulmonary compliance and resistance were related to sternal length (SE) in order to compare patients of various size and lung capacity. Height is another body measurement which has been used as an index of lung capacity in children. ${ }^{4} \mathrm{Al}$ though stemal length to our knowledge has not been used before for this purpose, we investigated this possibility since sternal length is easier to accurately measure in the infant than height and since infants comprised a significant percentage of patients in the study. To examine the relation between these two indices, a random 


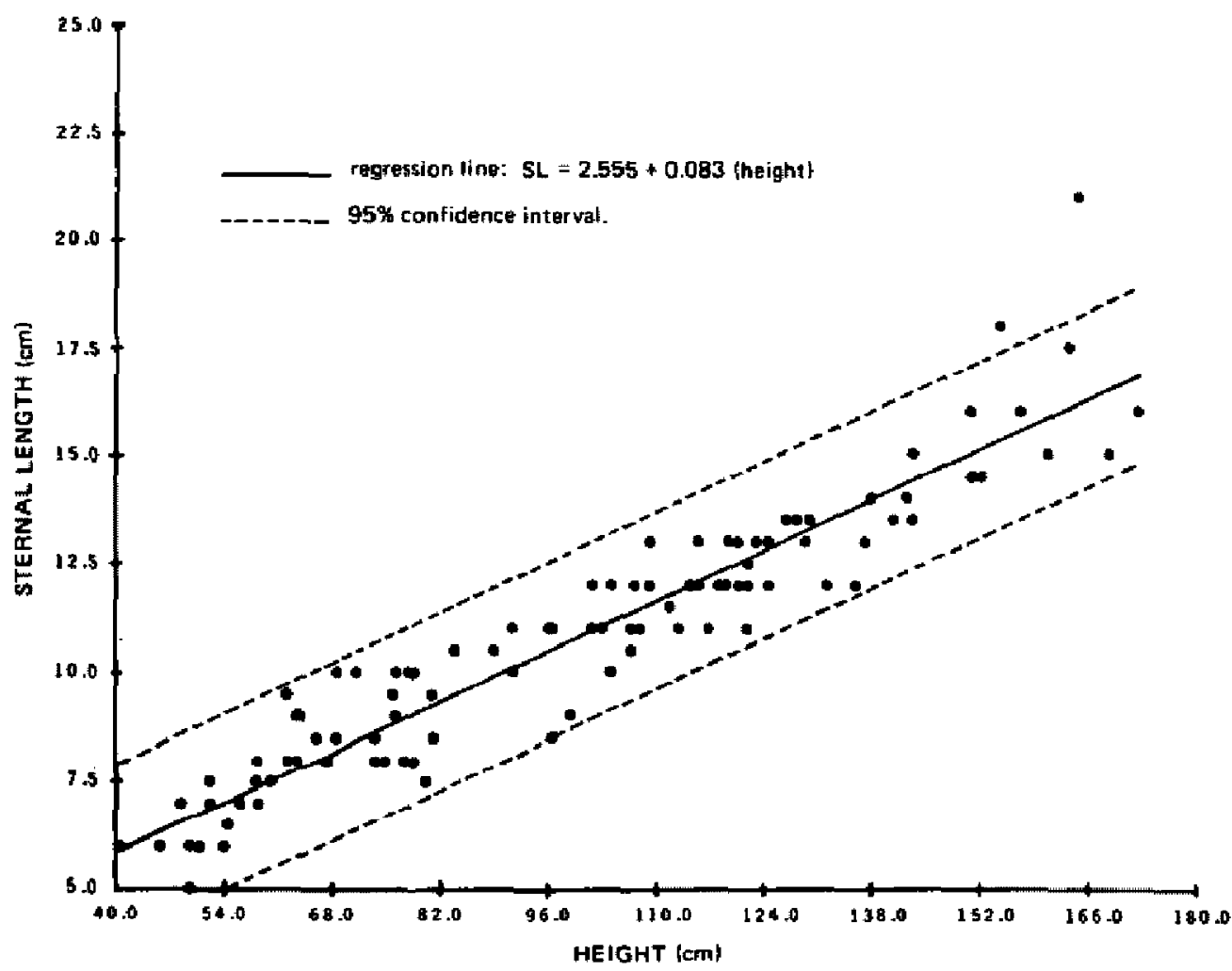

Frcune 2. Relationship of sternal length and height in 100 patients (see text). There is a high degree of correlation between sternal length and height $\left(r=0.942 ; p<0.001_{;} \mathrm{A}^{2}=88.78\right)$.

selection of one hundred patients from the newborn period to 15 years of age were carefully measured for height and sternal length. None of these patients were otherwise involved in our respiratory study. Sternal length was the distance in centimeters between the jugular notch and the base of the xiphoid, measured with a blunt-tipped caliper. Height was the heel to vertex distance in centimeters. Since an excellent correlation ( $\mathrm{r}=0.942$ ) was found between height and sternal length, the latter was chosen for its advantages - as pointed out above - to compare patients of various lung capacity (Figure 2 ).

Two constants ( $b_{o_{1}}$ and $b_{R_{P I}}$ ) were determined to serve as control values for pulmonary compliance and resistance. The constants are the regression coefficients (or slopes) for the relationships of $\log \mathrm{C}_{\mathrm{t}}$ and $\log \mathrm{R}_{\mathrm{P}_{\mathrm{t}}}$ to $\log \mathrm{SL}$ in control patients. If these relationships are linear, the slopes of the regression lines are constants for all normal patients regardless of size. These values can then be used as controls to be compared with values in patients with pulmonary disease. The slopes are calculated using the following formulae:

$$
\frac{C_{L} \text { regression coefficient }}{\log C_{L} \text { vs } \log S L}-b_{C_{L}}-\text { slope for curve of }
$$




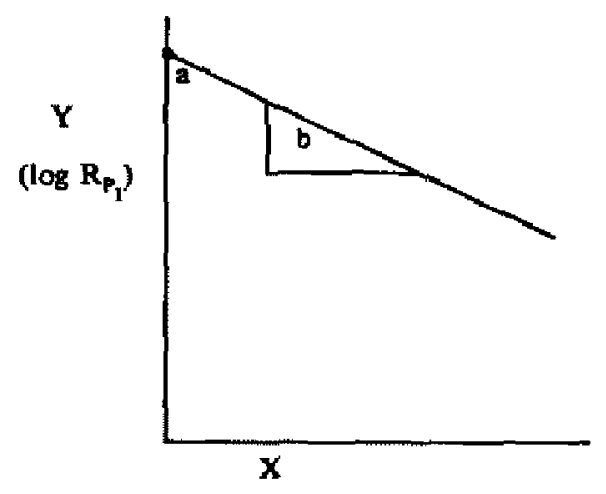

$$
\begin{gathered}
(\log S L) \\
Y=a+b x \\
\log C_{L}=a+b_{C_{L}} \cdot \log S L \\
\text { rearrange: } \\
b_{C_{L}}=\frac{\log C_{L}-a}{\log S L}=\text { slope }
\end{gathered}
$$

$a$ is the zero intercept on the $Y$ axis. $a$ was assumed constant for all patients, and was calculated to be -1.61 (see fig. 3), the zero intercept for group I and II patients. Thus -1.61 was used to determine $b_{\mathrm{C}_{\mathrm{L}}}$ for all patients studied.

$$
\frac{R_{\mathbf{P}_{\mathbf{I}}} \text { regression coefficient }}{R_{\mathbf{P}_{\mathbf{I}}} \text { vs } \log S L}-b_{\mathbf{R}_{\mathbf{P}_{\mathbf{I}}}}-\text { slope for curve of } \log
$$

$$
\begin{aligned}
& \underbrace{\left(\log C_{2}\right)}_{x} \\
& \text { ( } \log \text { SL) } \\
& \mathbf{Y}=\mathbf{a}+\mathbf{b x} \\
& \log \mathbf{R}_{\mathbf{P}_{\mathbf{I}}}=\mathbf{a}+\mathbf{b} \mathbf{R}_{\mathbf{P}_{\mathbf{t}}} \cdot \log \mathrm{SL} \\
& \text { rearrange: } \\
& \mathrm{bR}_{\mathrm{PI}_{\mathrm{I}}}=\frac{\log \mathrm{R}_{\mathrm{PI}_{\mathrm{I}}-a}-a}{\log \mathrm{L}_{\mathrm{L}}}=\text { slope }
\end{aligned}
$$


$a$ is the zero intercept on the $Y$ axis. $a$ was assumed constant for all patients, and was calculated to be +3.81 (see fig. 4), the zero intercept for group I and II patients. Thus 3.81 was used to determine $b_{n_{p},}$ for all patients studied.

Finally, the relationship between transpulmonary pressure and both compliance and resistance was examined in all patients by plotting Ptp $v b_{\mathrm{O}_{\mathrm{L}}}$ and $b_{\mathrm{F}_{\mathrm{P}_{1}}}$. This was done to determine if Ptp is a reliable index of changes in both pulmonary compliance and total inspiratory resistance.

\section{Results}

The mean tracheal pressure change, oesophageal pressure change, transpulmonary pressure, and blood carbon dioxide tension for all groups are reported in Table II. The mean transpulmonary pressure of the control group and group II stayed under $10 \mathrm{~cm}$ of water, but it was significantly increased in III and IV compared to controls $(\mathrm{p}<0.001$ ). All patients in group IV had transpulmonary pressures greater than $20 \mathrm{~cm}$ water. It is also evident from Table II that with a tracheal pressure of under $20 \mathrm{~cm}$ water and a respiratory frequency of between 20 to 26 per minute, depending on age, mild overventilation $\left(\mathrm{PaCO}_{2}<40\right.$ torr $)$ was produced in all groups, except group IV.

TABLE II

Results of Pressure Measurements and Corresponding $\mathrm{CO}_{2}$ Tehsion Levels (Arithmetic Mean for Group $\pm 95 \%$ Confidence Interval)

\begin{tabular}{|c|c|c|c|c|c|}
\hline Group & $\underset{\operatorname{cm} \mathrm{H}_{2} \mathrm{O}}{\stackrel{\Delta \mathrm{P}_{\mathrm{T}}}{ }}$ & $\underset{\mathrm{cm} \mathbf{H}_{2} \mathrm{O}}{\Delta \mathrm{P}_{\mathrm{B}}}$ & $\underset{\mathrm{cm}}{\mathrm{Ptp}} \mathrm{H}_{2} \mathrm{O}$ & $\frac{\text { Ptp }}{\text { p value }^{*}}$ & $\underset{\text { tort }}{\mathrm{PaCO}_{2}}$ \\
\hline $\begin{array}{l}\text { I } \\
\text { II } \\
\text { III } \\
\text { IV }\end{array}$ & $\begin{array}{l}15.3 \pm 1.0 \\
13.1 \pm 1.1 \\
17.5 \pm 2.5 \\
35.5 \pm 10.8\end{array}$ & $\begin{array}{l}5.9 \pm 0.6 \\
5.1 \pm 0.5 \\
4.3 \pm 0.5 \\
5.1 \pm 0.6\end{array}$ & $\begin{array}{r}9.5 \pm 0.8 \\
8.7 \pm 1.1 \\
13.2 \pm 2.4 \\
30.1 \pm 7.4\end{array}$ & $\begin{array}{l}>0.1 \\
<0.001 \dagger \\
<0.001 \dagger\end{array}$ & $\begin{array}{l}32.4 \pm 1.9 \\
33.4 \pm 1.7 \\
32.9 \pm 2.3 \\
43.3 \pm 5.6\end{array}$ \\
\hline
\end{tabular}

*p values (Student's t test) test for significant difference between group II vs I, group III vs I plus II, and group IV ws I plus II.

tSignificant difference.

A good linear fit was found between a plot of $\log C_{L}$ vs $\log S L(r=0.805)$ and between $\log R_{P_{I}}$ vs $\log S L$ ( $r=-0.754$ ) for groups I and II, without significant differences between these groups (Figs. 3 and 4 ).

Table III contains the mean values of the regression coefficients $\left(b_{\mathrm{C}_{L}}\right.$ and $\left.\mathrm{b}_{\mathrm{R}_{\mathrm{P}_{1}}}\right)$ for all groups. Since there was no significant difference between the corresponding mean b values of groups I and II, these two groups were combined to represent the baseline for the study. The mean b levels for groups III and IV were compared to the baseline group and were found to be significantly different.

Figures 5 and 6 describe the relationship between transpulmonary pressure and both $\mathrm{b}_{\mathrm{C}_{\mathrm{L}}}$ and $\mathrm{b}_{\mathrm{R}_{\mathrm{F}_{\mathrm{T}}}}$ respectively, for all patients. Although the correlation of $P t p$ was more linear with $b_{C_{2}}(r=-0.777)$ than with $b_{R_{P_{1}}}(r=0.537)$, it can be seen that Ptp varied inversely with changes in compliance and directly with changes in resistance. 


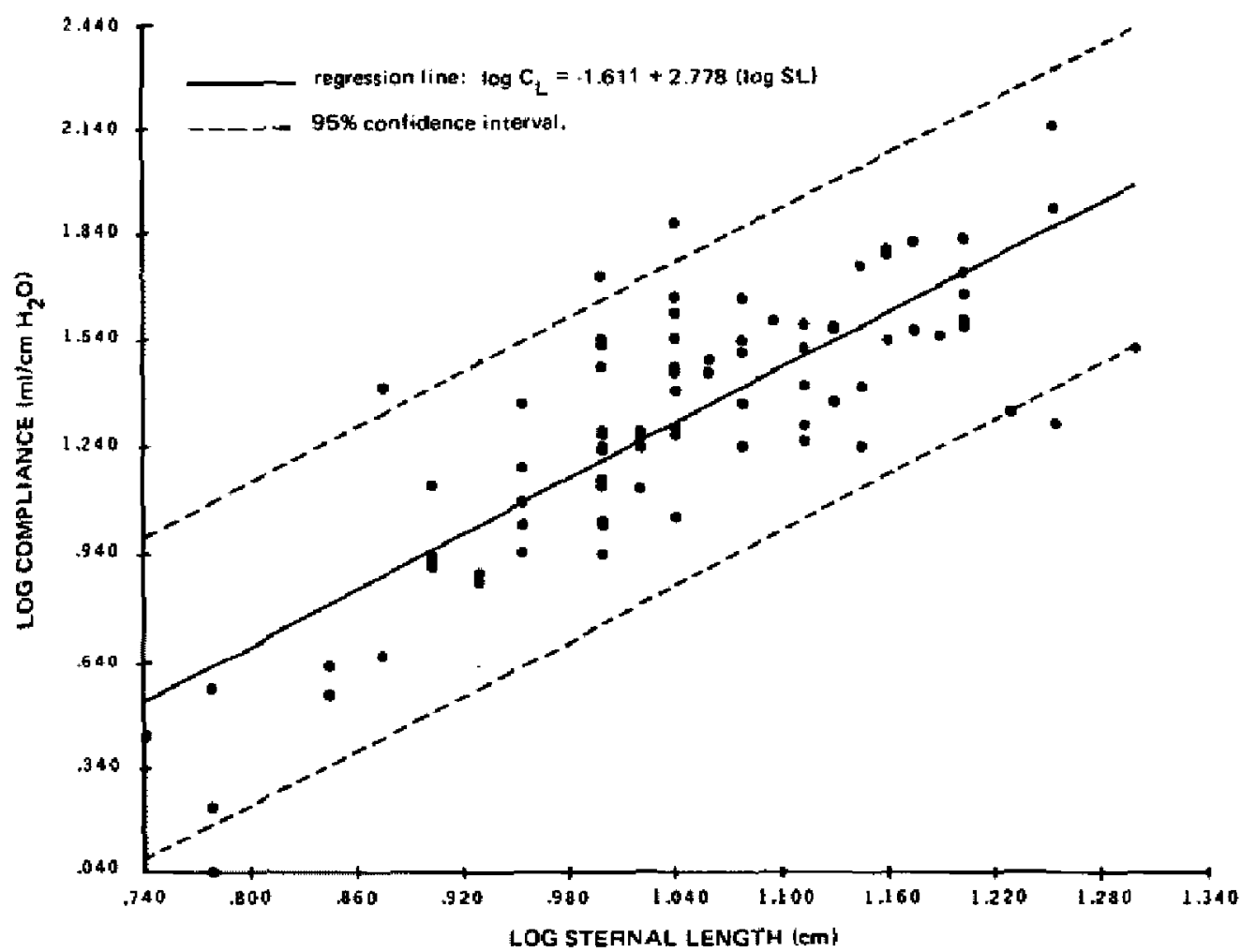

Figune 3. Relationship of $\log C_{L}$ and $\log$ SL for groups $I$ and II. A linear relationship was found $\left(\mathrm{x}=0.805 ; \mathrm{p}<0.0 \mathrm{I} ; \mathrm{H}^{2}=64.7 \%\right)$, without significant differences between groups I and II. The control b value of 2.78 is taken from the regression equation ( see text).

\section{Discussion}

Physiologic parameters such as blood $\mathrm{CO}_{2}$ tension, physiological dead space to tidal volume ratios, and mean pulmonary artery pressure to mean aortic pressure ratios have been used to define acute respiratory failure in infants following cardiac surgery. ${ }^{7}$ However, normal preoperative levels for these parameters did not necessarily eliminate the possibility of respiratory failure after surgery. We therefore decided to investigate another measurement of respiratory function which might contribute further to the forecast of respiratory failure.

The inspiratory transpulmonary pressure ( $P$ t ) required to produce adequate alveolar ventilation, that is a $\mathrm{PaCO}_{2}$ from 30 to 35 torr, in patients undergoing artificial respiration was chosen as a readily obtainable parameter of respiratory function. Ptp as measured in this study is the pressure differential needed to overcome resistive forces which oppose expansion of the lungs. An elevation in these forces, and therefore in Ptp, noted in patients with increased pulmonary blood flow and pulmonary arterial hypertension, ${ }^{8}$ as well as in other paediatric patients requiring ventilatory assistance, ${ }^{8}$ should result in an increase in the work of breathing. When added to the stress of surgery, this increased work of breathing might then lead to acute respiratory failure in the postoperative period. 


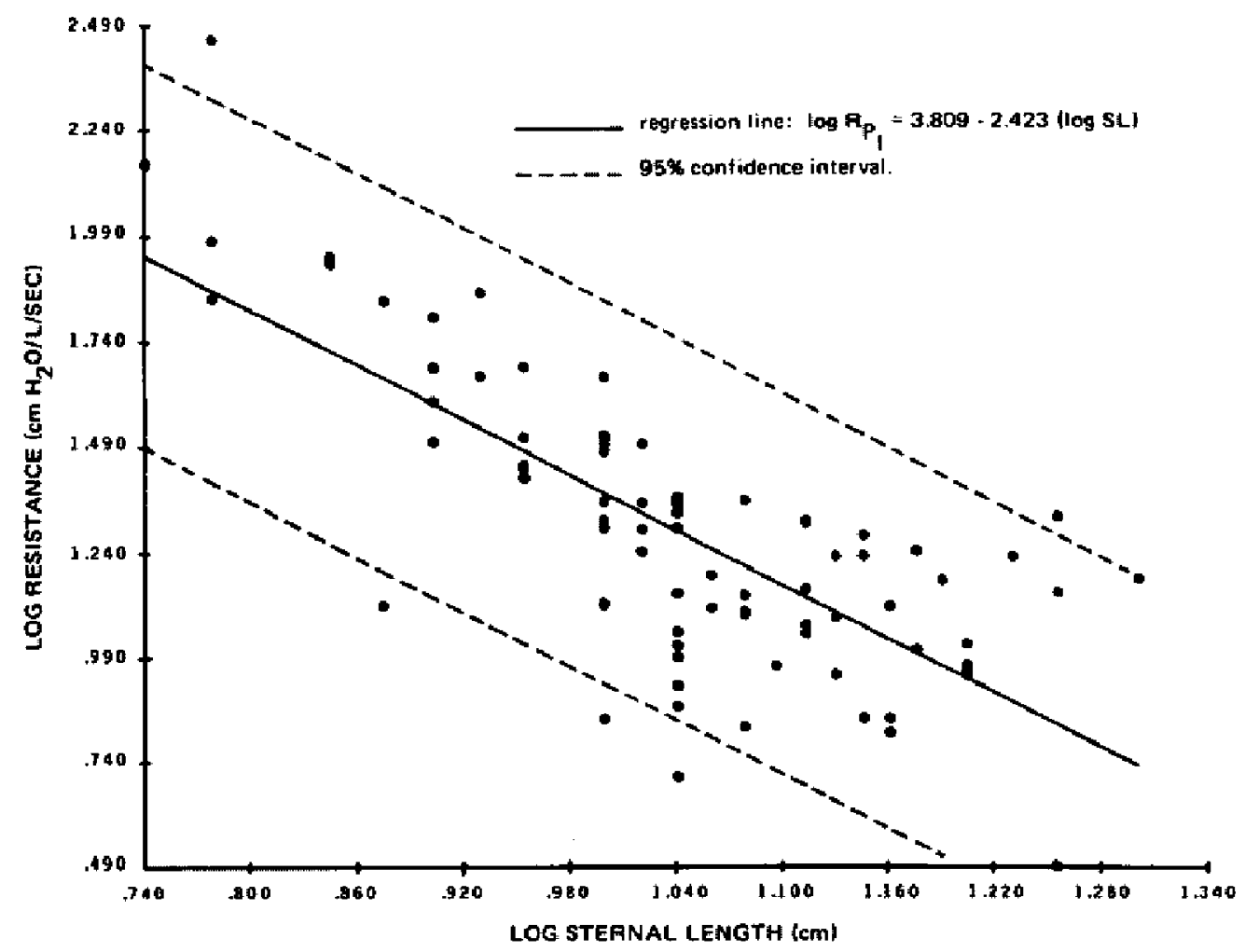

Figure 4. Relationship of $\log \lambda_{P_{1}}$ and $\log$ SL for groups $I$ and II. A linear relationship was found ( $\mathrm{r}=-0.754 ; \mathrm{p}<0.01 ; \mathrm{R}^{2}=56.8 \%$ ), without significant differences between groups $\mathrm{I}$ and II. The control b value of 2.42 is taken from the regression equation (see text).

A good degree of linearity was found when $\log C_{L}$ and $\log \mathbf{R}_{\mathbf{P}_{\mathbf{I}}}$ were related to $\log$ SL in control patients. The slopes of these relationships are therefore constants which may be compared to values obtained by similar methods in patients of all sizes with cardiopulmonary disease. The slopes (b levels) for patients with pulmonary hypertension ( $\mathrm{Gp}$ III) were significantly different from controls with some overlap of 95 per cent confidence intervals. As expected, patients with respiratory failure ( $\mathrm{G} p \mathrm{IV}$ ) had $\mathrm{C}_{\mathrm{k}}$ and $\mathrm{R}_{\mathrm{P}_{\mathrm{L}}}$ b values very different from all other groups. Since $P t p$ varied inversely with $b_{C_{L}}$ and directly with $b_{R_{P_{I}}}$, an elevation in Ptp reflected an increase in the forces resisting expansion of the lungs and the work required to overcome these forces during spontaneous respirations.

This paper reports the range of Ptp for paediatric patients with and without cardiopulmonary disease. Patients able to breathe spontaneously after operation had Ptp values less than $20 \mathrm{~cm}$ water before and during surgery. Only in patients requiring ventilatory assistance after surgery was $P$ tp greater than $20 \mathrm{~cm}$ water intraoperatively. None of these patients were in respiratory failure before surgery. Therefore a Ptp $>20 \mathrm{~cm}$ water appears to have served as an indicator of impending respiratory failure in children anaesthetized for cardiac surgery. 
TABLE III

Regression Coefficients (Arithmetic Mean for Grour $\pm 95 \%$ Conftdence interval) FOR $\log \mathrm{CL}_{\mathrm{L}}$ AND $\log \mathrm{R}_{\mathrm{PI}}$ vs $\log \mathrm{SL}$

\begin{tabular}{|c|c|c|c|c|}
\hline Group & $\begin{array}{c}\mathrm{b}_{\mathrm{O}_{\mathrm{L}}} \\
\mathrm{ml} / \mathrm{cm} \mathrm{H}_{2} \mathrm{O} / \mathrm{cm} \mathrm{SL}\end{array}$ & $\frac{b_{\mathbf{L}}}{\text { p value* }}$ & $\frac{b_{R p_{I}}}{\mathrm{~cm} \mathrm{H}_{2} \mathrm{O} / \mathrm{L} / \mathrm{sec} / \mathrm{cm} \mathrm{SL}}$ & $\frac{\mathbf{b}_{\mathbf{R}_{\mathbf{I}}}}{\mathrm{p} \text { value* }}$ \\
\hline $\begin{array}{l}\text { I } \\
\text { III } \\
\text { IV }\end{array}$ & $\begin{array}{l}2.76 \pm 0.08 \\
2.83 \pm 0.12 \\
2.60 \pm 0.15 \\
2.09 \pm 0.18\end{array}$ & $\begin{array}{l}>0.5 \\
<0.01 \dagger \\
<0.001 \dagger\end{array}$ & $\begin{array}{l}2.38 \pm 0.09 \\
2.47 \pm 0.09 \\
2.33 \pm 0.16 \\
1.90 \pm 0.09\end{array}$ & $\begin{array}{l}>0.7 \\
<0.01 \dagger \\
<0.001 \dagger\end{array}$ \\
\hline
\end{tabular}

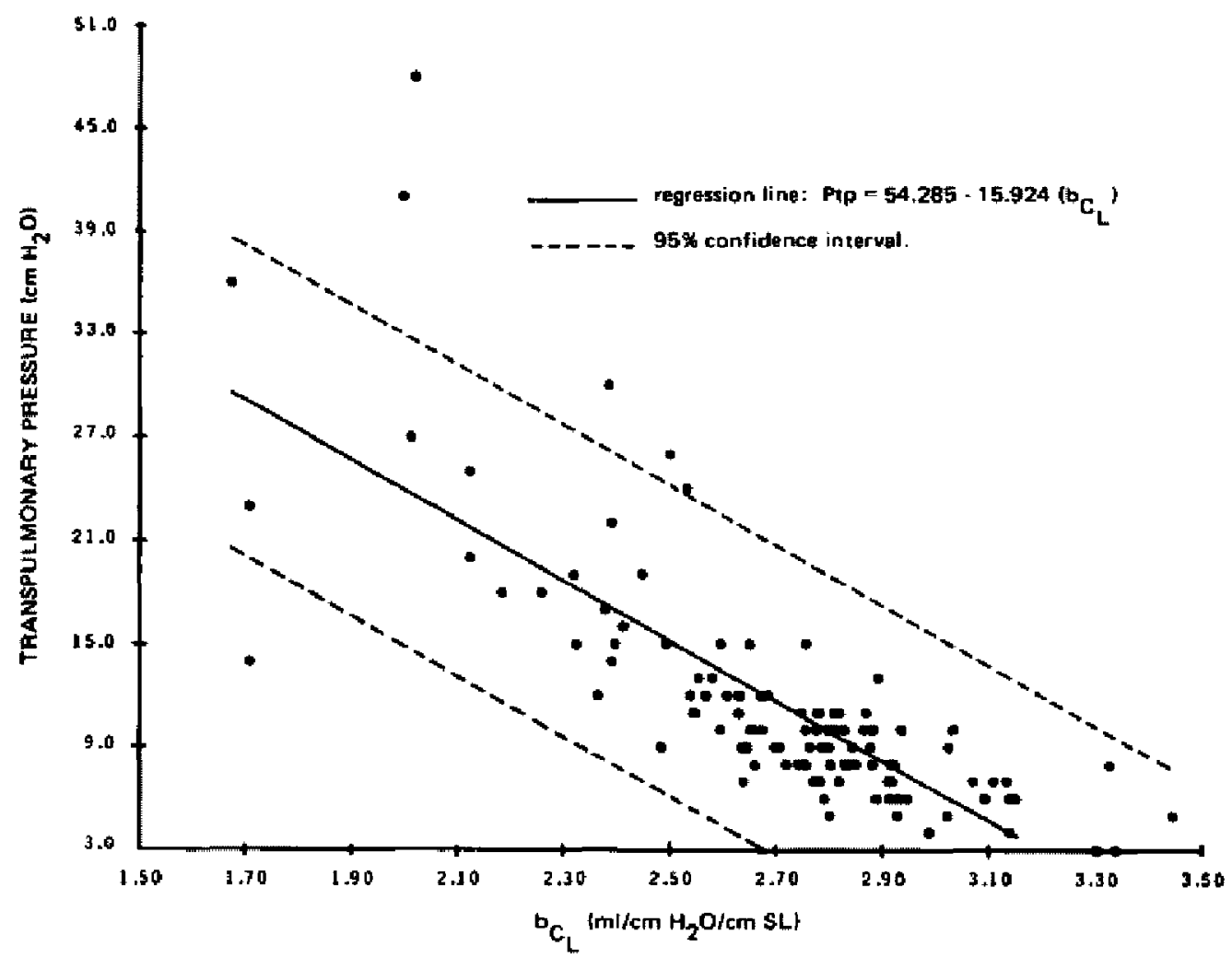

Figuae 5. Relationship of $\mathrm{Ptp}_{\mathrm{p}}$ and $\mathrm{b}_{\mathrm{e}}$ for all patients studied. $\mathrm{Ptp}$ and $\mathrm{b}_{\mathrm{c}}$ are inversely related $\left(r=-0.777 ; \mathrm{p}<0.01 ; \mathrm{R}^{2}=60.4 x\right)$. 


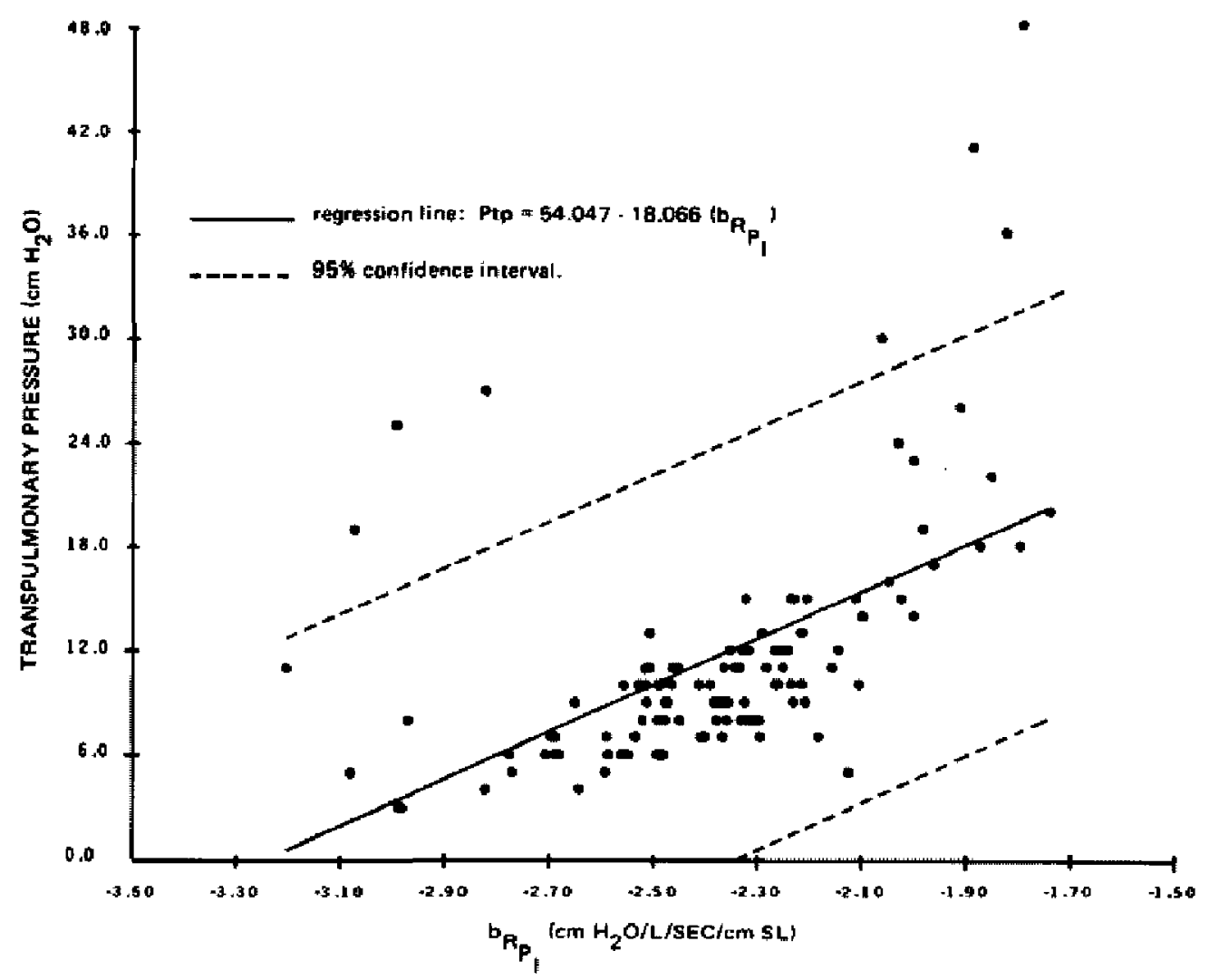

Figune 6. Relationship of $P t p$ and $b_{R_{1}}$ for all patients studied. All values are negative numbers; thus there is lesser negativity (larger values) from left to right on abscissa. $P$ tp and $b_{\mathbf{F p}_{1}}$ are directly related $\left(\mathrm{r}=0.537 ; \mathrm{p}<0.05 ; \mathrm{H}^{2}=28.8 \%\right.$ ).

It is recognized that in addition to an elevation in resistive forces opposing spontaneous respirations, respiratory failure may also occur in these patients secondary to cardiovascular and neurological complications. Consequently Ptp is a measure of pulmonary function which should be employed always keeping in mind other pathology that could cause respiratory failure in the postoperative period.

\section{SUMMARY}

To find a practical objective parameter indicating the need for ventilatory assistance in paediatric patients after cardiac surgery, measurements were made of transpulmonary pressure, pulmonary compliance and inspiratory pulmonary resistance in 121 anaesthetized infants and children while they were being ventilated by a volume controlled respirator. Transpulmonary pressure, defined as that transpulmonary pressure required to produce a $\mathrm{PaCO}_{2}$ from 30 to 35 torr, varied inversely with pulmonary compliance and directly with inspiratory pulmonary resistance, reflecting changes in the forces resisting expansion of the lungs. Transpulmonary pressure greater than $20 \mathrm{~cm}$ water intraoperatively was present only in patients requiring ventilatory assistance after surgery. Transpulmonary pressure therefore 
was found to be an objective parameter of pulmonary function which can be measured intraoperatively and could be used to help forecast impending respiratory failure in the postoperative period.

\section{Rísumé}

Le but de cette étude était de trouver un paramètre objectif qui indiquerait le besoin d'une assistance ventilatoire chez les enfants apres la chirurgie cardiaque. Nous avons fait des évaluations de la pression transpulmonaire, de la compliance pulmonaire et de la résistance pulmonaire inspiratoire chez 121 enfants ventilés pour un respirateur à volume contrôlé. L'âge des enfants allait de une semaine à 15 ans. Les porteurs de maladie cardiaque congénitale présentaient une variété de pathologies cardiaques requérant des traitements soit à cour ouvert, soit à coeur fermé. La conduite de lanesthésie a consisté à donner du protoxyde d'azote et de loxygène $50: 50$ et du fuothane à 1.5 pour cent et de la ventilation artificielle.

Chez les porteurs d'hypertension pulmonaire, la compliance était diminuée et la résistance inspiratoire augmentée. La pression transpulmonaire nécessaire pour conserver une $\mathrm{PaCO}_{2}$ de 30 à $35 \mathrm{~mm} \mathrm{Hg}$ a varié de façon inversement proportionnelle a la résistance inspiratoire, ce qui donne une idée du changement des forces pour l'expansion des poumons.

Aussi, la pression transpulmonaire per-opératoire s"est avérée inférieure à $20 \mathrm{~cm}$ d'eau chez tous les malades capables de se ventiler spontanément, adéquatement au cours des suites opératoires. La pression a dépassé $20 \mathrm{~cm}$ d'eau seulement chez les malades requérant une assistance ventilatoire après la chinurgie. Etant donné que les mesures de la pression transpulmonaire inspiratoire peuvent se faire en cours d'opération, ce paramètre peut devenir un outil indicateur utile pour prédire les besoins d’assistance ventilatoire post-opératoire.

\section{REFERENCES}

1. Damman, J.A., JR, Thung, N., Chaistrieb, I.I., Littlefiec.d, J.B., \& Muller, W.H. The management of the severely ill patient after open-heart surgery. J. Thorac. and Cardiovas. Surg., 45: 80 (1983).

2. Moffit, E.A., Sesslen, A.D., \& Krexin, J.W. Postoperative care in open-heart surgery. J. Am. Med. Assn., I99: 129 ( 1967 ).

3. MEAD, J. Mechanical properties of lungs. Physiol. Rev., $41: 281$ (1961).

4. KaIecer, I. Studies on mechanics of respiration in infancy. Amer. J. Dis. Child., 105: 439 (1963).

5. Swyer, P.R., Reman, R.C., \& Whight, J.J. Ventilation and ventilatory mechanies in the newborn. J. Pediat, $56: 612(1960)$.

8. Reynomos, R.N. \& ETsteN, B.E. Mechanies of respiration in apneic anesthetized infants. Anesthesiology, 27, 13 (1966).

7. Downes, J.J., Niconemus, H.F., Pierce, W.S., W Wldfausen, J.A. Acute respiratory failure in infants following cardiovascular surgery. J. Thorac. and Cardiovas. Surg., 59: 21 (1970).

8. Deal, C., Oshona, J.J., Milcer, G.E., Gerhode, F, Pulmonary compliance in congenital heart disease and its relation to cardiopulmonary bypass. J. Thorac. and Cardiovas, Surg., 55: 320 (1968).

9. Thomas, D.V., Fletcher, G., Sunshine, P., Schaffer, I.A, \& Klaus, M.H. Prolonged respirator use in pulmonary insufficiency of newborn. J. Am. Med. Assn., 193: 183 (1965). 